\title{
BM] open The development, feasibility and acceptability of a school-based obesity prevention programme: results from three phases of piloting
}

\author{
Katrina M Wyatt, ${ }^{1}$ Jennifer J Lloyd, ${ }^{1}$ Siobhan Creanor, ${ }^{2}$ Stuart Logan ${ }^{1}$
}

To cite: Wyatt KM, Lloyd JJ, Creanor S, et al. The development, feasibility and acceptability of a school-based obesity prevention programme: results from three phases of piloting. BMJ Open 2011;1: e000026. doi:10.1136/ bmjopen-2010-000026

- Prepublication history for this paper is available online. To view these files please visit the journal online (http:// bmjopen.bmj.com).

Received 1 December 2010 Accepted 12 April 2011

This final article is available for use under the terms of the Creative Commons Attribution Non-Commercial 2.0 Licence; see http://bmjopen.bmj.com

\footnotetext{
${ }^{1}$ Institute for Health Service Research, Peninsula College of Medicine and Dentistry, University of Exeter, Exeter, UK

${ }^{2}$ Centre for Health and Environmental Statistics, University of Plymouth, Plymouth, UK
}

\section{ABSTRACT}

Objectives: To develop a school-based obesity prevention programme and evaluate the feasibility and acceptability of the intervention and the planned definitive cluster randomised trial.

Design: This was a three stage pilot involving six schools (398 children) in South West England, including an exploratory randomised controlled trial and qualitative interviews and focus groups with teachers, parents and children.

Intervention: The Healthy Lifestyle Programme uses a range of school-based activities including lessons, assemblies, parents' evenings, interactive drama workshops and goal setting to engage schools, children and their families.

Results: Of the 398 eligible children in the three pilot phases, only four opted out and a further three withdrew from the exploratory trial. In the exploratory trial, baseline measurements (anthropometric and behavioural) were obtained for 202/204 eligible children in four schools and both 18- and 24-month outcome measurements for 193/204 and 187/204 participants, respectively. Qualitative data show that delivery of the intervention is feasible within schools and acceptable to teachers, children and families. In the exploratory trial, $18 / 80$ children $(24 \%)$ in the intervention schools and $31 / 122(26 \%)$ in the control schools were overweight or obese at baseline, increasing, at 18-month follow-up, to $38 / 119(32 \%)$ in the control schools compared with $18 / 74(24 \%)$ in the intervention schools. At 24 months the proportion of overweight and obese children in the control schools remained at $32 \%$ (36/114), whereas the proportion in the intervention schools decreased slightly to $22 \%$ $(16 / 73)$

Conclusion: The Healthy Lifestyle Programme is feasible to deliver and acceptable to schools, children and their families. We recruited, retained and obtained outcome measurements from $92 \%$ of eligible children in the exploratory trial, including measurements taken after transition to secondary school, suggesting that a definitive trial is likely to be deliverable.

\section{BACKGROUND}

There has been a substantial increase in the proportion of children in the UK who are overweight. The Health Survey for England (2008) reported that $19 \%$ of girls and $18 \%$ of boys aged $11-15$ were obese and $34 \%$ of girls and boys were overweight or obese. ${ }^{1}$ The National Child Measurement Programme $(2009 / 2010)$ reported that by age 10-11 years (school year 6), one in three children in England were either overweight or obese. ${ }^{2}$ Being overweight in childhood is associated with adverse consequences including metabolic abnormalities, increased risk of type II diabetes, and musculoskeletal and psychological problems. ${ }^{3}$ Over $50 \%$ of obese children become obese adults ${ }^{4}$ with significant health consequences. ${ }^{5}$

Obesity results from an imbalance between consumption and expenditure of energy. Epidemiological studies suggest a number of risk factors, the strongest of which is having one or more overweight parents, ${ }^{6}$ and there are also strong associations between the risk of overweight and socioeconomic status, diet, physical activity levels and other lifestyle factors. ${ }^{7}$ At a population level, the consumption of processed and fast food, including sweetened fizzy drinks, has increased, while that of fruit and vegetables has declined and portion sizes of pre-packaged food have increased substantially. ${ }^{8}$

The association with overweight and obesity and physical activity remains contested, with cross-sectional studies showing a reduction in levels and intensity of physical activity in children and an increase in $\%$ body fat. ${ }^{9}$ Longitudinal studies are scarce, although recent data suggest that fatness leads to a reduction in physical activity rather than the other way round. ${ }^{10}$ Some studies have reported an association between time spent watching television and obesity. ${ }^{11}$ Not only is television viewing a sedentary activity, but it is 


\section{ARTICLE SUMMARY}

Article focus

- To show the development and evaluation of a novel school-based obesity prevention programme through three detailed stages of piloting.

- To demonstrate the acceptability of the Healthy Lifestyle Programme (HeLP) to schools, children and their families.

- To present evidence showing the feasibility of the trial design and outcome measurements through an exploratory trial involving four schools and 202 children.

\section{Key messages}

- HeLP has been systematically developed and uses dramabased activities to engage the school, children and their families in healthy lifestyle messages and activities.

- The programme has been piloted in six schools involving 398 children and results suggest that it is acceptable and feasible for schools, children and their families.

- Results from the pilot phases have provided sufficient evidence to support the evaluation of the HeLP intervention in a full scale trial.

\section{Strengths and limitations of this study}

Strengths

- The HeLP intervention has undergone a systematic development process using research evidence, behavioural theory, stakeholder consultation and piloting. This has enabled the researchers to gain a deeper understanding of the context in which the intervention is to be delivered in order to maximise engagement at all levels. Preliminary results suggest the programme may affect behaviours associated with overweight and obesity.

\section{Limitations}

- Interviews and focus groups were conducted by the lead researcher who had built up a relationship with the schools, children and their families. This may have affected responses as the participants might not have wanted to express negative opinions. However, the ongoing support and retention of the schools and children would suggest that if there was such an effect, it was very slight. Piloting has taken place in schools in varying socioeconomic areas, and although there is a limited ethnic mix of children in South West England, the drama framework has been specifically developed to allow flexibility and adaptation to ensure it is recognising and responding to the needs of the children receiving it.

also positively correlated with total calorific intake ${ }^{12}$ and the consumption of snack foods. ${ }^{13}$

More recently, community-wide approaches to preventing and reducing obesity in children have been developed and evaluated. ${ }^{14}{ }^{15}$ These initiatives take a multistrategy, multisite approach with school-based interventions forming part of the overall programme of events.

The most recent systematic review (2008) of controlled trials of school-based interventions concluded that interventions which increase activity and reduce sedentary behaviour may help children to maintain a healthy weight, although results were short term and inconsistent. ${ }^{16}$ The review also reported that trials of dietary interventions also produced inconsistent results, although the reviewers suggest that a combined approach may be more effective in preventing children becoming overweight in the long term.

The Healthy Lifestyle Programme (HeLP) is a schoolbased intervention which seeks to deliver healthy lifestyle messages and provide simple individually tailored strategies to assist change relating to healthy activity and eating. HeLP takes a population approach seeking to change behaviour at a family as well as at an individual and institutional level. The development of HeLP followed the Medical Research Council (MRC) guidance for the development and evaluation of complex interventions. ${ }^{17}$ This paper reports on the iterative development and refinement of HeLP, in accordance with the 'development' and the 'feasibility and piloting' processes of the MRC framework, and presents results from an initial development phase, a 'proof of concept' phase and an exploratory trial.

\section{DEVELOPIMENT, FEASIBILITY AND PILOTING METHODS}

The intervention was developed using an Intervention Mapping protocol ${ }^{18}$ utilising research evidence, behavioural theory, extensive stakeholder consultation and piloting to develop key behavioural objectives for each target group (teachers, children and parents) and specific intervention techniques and strategies that linked directly to them. HeLP aims to deliver a general healthy lifestyle message relating to the energy balance and within this context, three evidence-based key messages are emphasised: a decrease in the consumption of sweetened fizzy drinks, an increase in the proportion of healthy snacks consumed and a reduction in TV viewing and other screen-based activities. These messages are consistent with the strategies suggested in the NICE guidance. ${ }^{19}$ As a means of communicating these messages in a simple and easy to remember way, we used the logo ' $80 / 20$ ', suggesting we should aim to eat healthily and be active $80 \%$ of the time. We hypothesised that this approach would enable children and their families to negotiate and have control over the choices they make, an important consideration in behaviour change. ${ }^{20}$ Process evaluation methods during all three phases included semi-structured interviews with staff and parents, focus groups with children, questionnaire responses from children and parents, documentation of child, parental and staff involvement, and observation of intervention delivery.

\section{Phase 1: Assess range of delivery methods for key} objectives identified in the Intervention Mapping process (2005-2006; one school, $n=119$ children aged 8-11)

We worked with children, parents and teachers from a single primary school to try candidate behaviour change approaches for different age groups. We delivered healthy lifestyle messages to three age groups (8-9-yearolds, 9-10-year-olds and 10-11-year-olds) using lessons and either interactive drama activities or goal setting 
Figure 1 Phase 1: Development study (2005-2006).

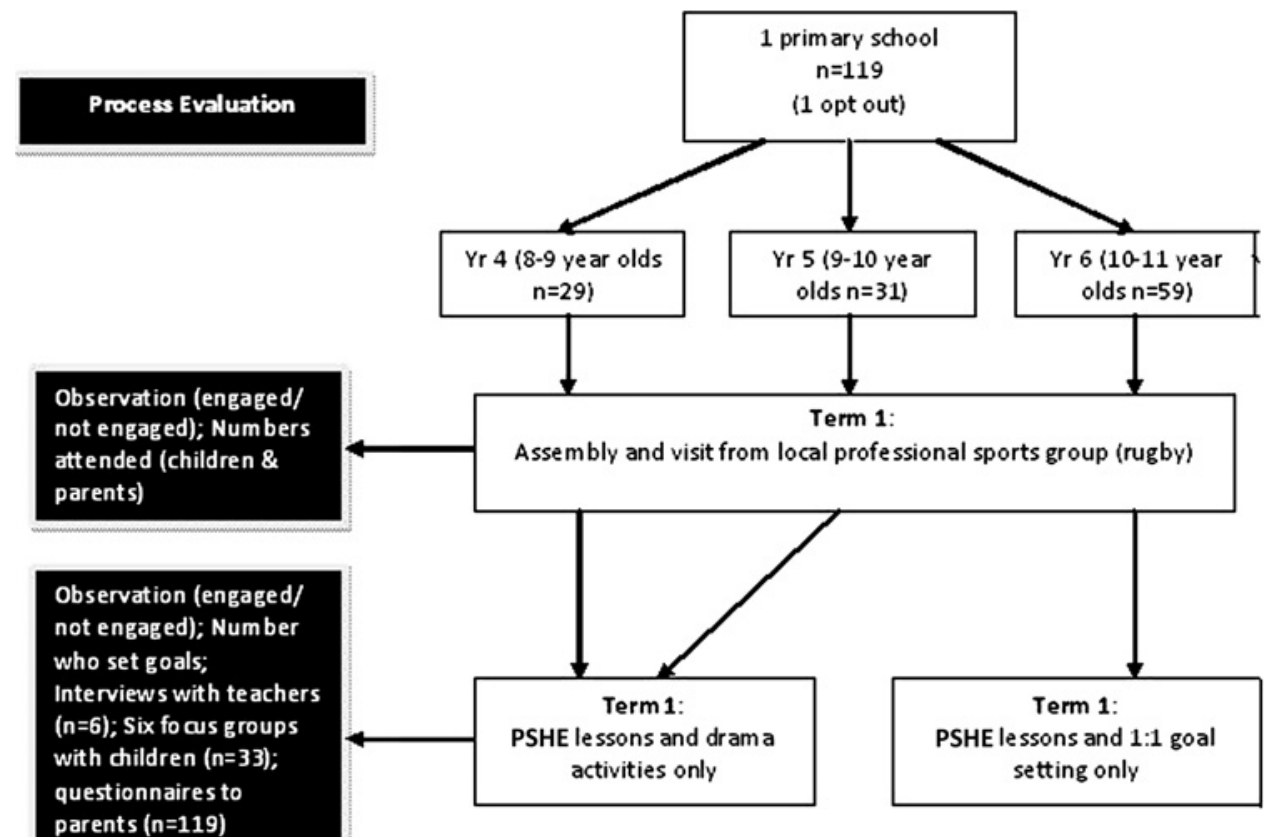

(figure 1). Six focus groups (two for each year group, $\mathrm{n}=33$ ) were held with the children to ascertain views on activities and what messages and concepts they remembered. Children whose parents consented to the focus groups were randomly selected to participate. Semistructured interviews were held with teachers $(n=6)$ and parents were invited to complete a questionnaire about the study.

Phase 2: Proof of concept-pilot of intervention and outcome measurements (2006-2008; one school, $n=77$ children aged 9-10)

Based on the results from the first phase, the intervention was further developed (figure 2) and evaluated in a second primary school in an area of high social deprivation, with three Year 5 classes. Baseline and 6week post-intervention height, weight, waist circumference, $\%$ body fat, objective physical activity, food intake and TV viewing/screen-based activity were assessed.

Food intake was assessed using the adapted version of the Food Intake Questionnaire, ${ }^{21}$ an adapted recall method which asks whether specific foods were consumed the previous day. Children completed the Food Intake Questionnaire twice in order to obtain a weekday and weekend food intake. TV viewing/screenbased usage was assessed using the adapted version of the Children's TV Viewing Habits Questionnaire. ${ }^{22}$ To assess physical activity, children were asked to wear a GT1M Actigraph (Actigraph LLC, Pensacola, Florida, USA; http://www.theactigraph.com) during waking hours over 7 consecutive days ( 5 weekdays and one weekend). Two focus groups (a total of 14 children) were held with children who 'engaged fully' (defined by enthusiasm for the study, desire to set and maintain goals) and a further focus group with those who appeared 'indifferent' (reluctant to take part in activities, needed several prompts regarding goals or did not want to set goals) to the study and the messages $(n=4)$. Interviews were held with the staff $(n=3)$ and head teacher $(n=1)$ and parents of the children $(n=5)$. Parents were also invited to complete a questionnaire about the study.

\section{Phase 3: Exploratory randomised controlled trial} (2008-2010; four schools (seven classes), $n=204$ children aged $9-10$ )

Phase 3 sought to assess, for schools, children and their families, recruitment and retention in control and intervention schools, the feasibility and acceptability of the HeLP intervention and of future trial outcome measurements, and facilitators and barriers to the uptake of the intervention. All state primary schools in Exeter were eligible to take part if they had at least one single age Year 5 group (ie, not Year $4 / 5$ or $5 / 6$ mixed classes). Schools were recruited via the Devon Association of Primary Headteachers. Baseline height, weight, waist circumference, $\%$ body fat, food intake, TV viewing/screen-based activity and physical activity (as in phase 2) were collected prior to randomisation (two control and two intervention schools). These same measurements were then collected 18 months after baseline and anthropometric measurements only were collected at 24 months after baseline, which involved tracking the children to their secondary school (figure 3). All anthropometric measurements at each time point were taken by an independent assessor blind to allocation. Six focus groups across the four schools (a total of 38 children) were carried out from a selection of children whose parents gave consent (groups were purposefully sampled to reflect gender mix and weight status) and semi-structured interviews were conducted with staff $(n=9)$ and parents $(n=17)$ in control and intervention schools. 
Figure 2 Phase 2: 'Proof of concept' study (2006-2007).

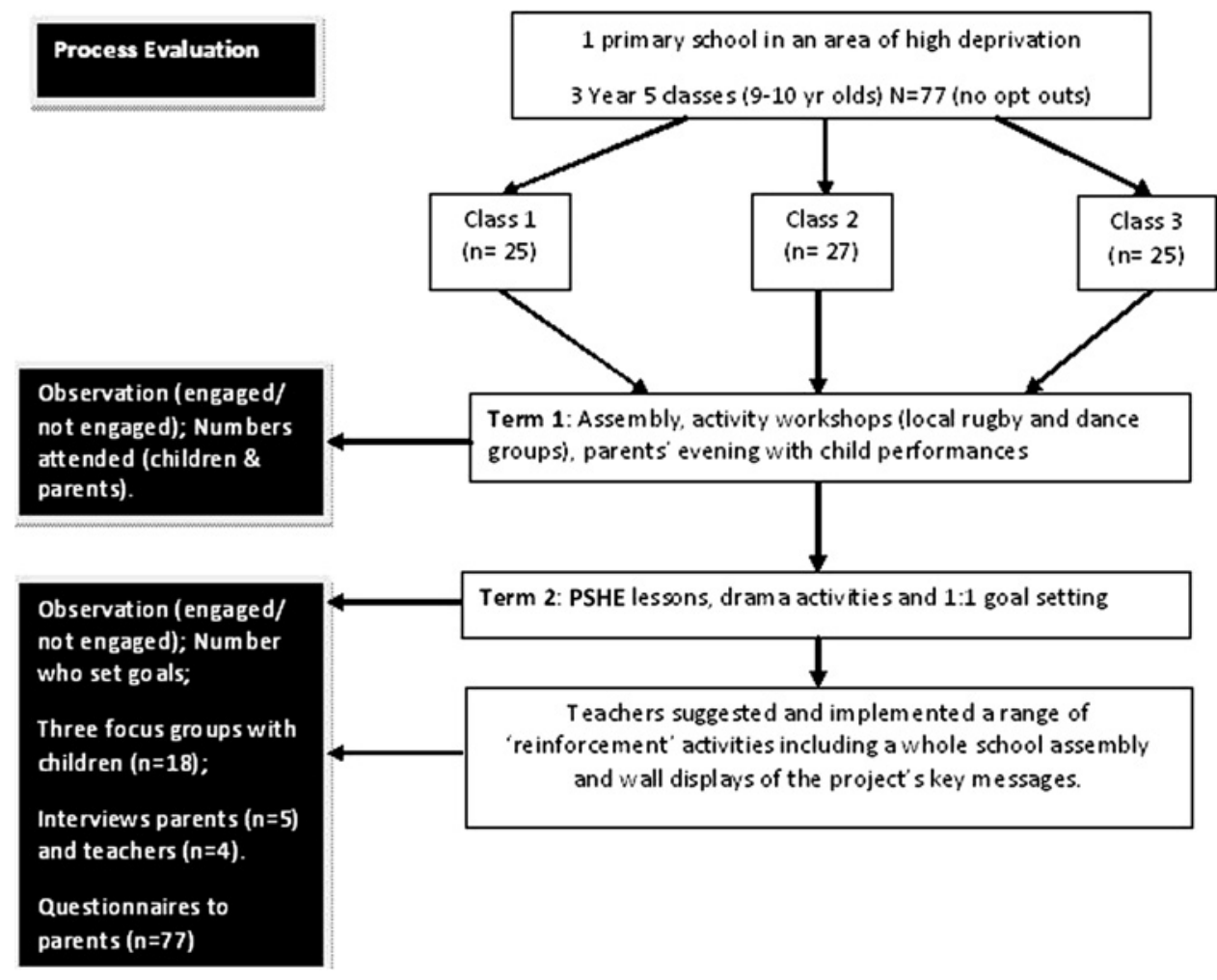

\section{RESULTS}

Phase 1

Of the 120 children invited to participate, only one child opted out (figure 1).

\section{User views}

Many parents reported in the questionnaire positive parent/family behaviour changes and qualitative data from teachers, children and their parents suggested that children in Year 5 (9-10-year-olds) were more receptive to the messages and more able and willing than the children in Year 4 and 6 to translate them into possible behaviour changes. In addition, it appeared that this year group engaged their families to the greatest extent. Teachers thought that the education lessons should be taught consecutively over 1 week to maintain momentum and that the drama and goal setting had the potential to work synergistically by engaging the children through the drama and following this up with encouraging the children, with their parents support, to make changes through setting simple goals. Parents and children also highlighted the need for a greater variety of activities to introduce the key messages and concepts in order to engage both boys and girls.

\section{Implications}

In order to build a trusting relationship, a range of activities were developed to introduce the school, children and their families to the project's key messages. A 'Healthy Lifestyles Week' was developed consisting of education lessons in the morning (delivered by teachers) which dovetailed with interactive drama activities in the afternoon (delivered by a local drama group).
In order to guide the sequential development of the intervention components across the school year, key performance objectives, developed using an Intervention Mapping process, were mapped onto the Health Action Process Model (HAPA) of behaviour change that suggests behaviour change occurs through a sequence of adoption (establish motivation), initiation (take action) and maintenance (stay motivated) processes. ${ }^{23}$ The intervention components at this stage of development were creating a receptive environment, a healthy lifestyles week and goal setting with Year 5 children (9-10-year-olds) as the target group.

\section{Phase 2}

No child opted out (figure 2) and no adverse events (eg, child feeling stigmatised) were reported by parents, teachers or children in questionnaires, focus groups or individual discussions. Self-report questionnaires and accelerometry data from the children suggested changes with respect to snacking and sedentary behaviour.

\section{User views}

Staff were enthusiastic about the programme, in part because it met the National Curriculum guidelines for Personal Social Health Education and Citizenship, and importantly because they felt it promoted families' engagement with the school. Some teachers felt that the drama had a positive effect on the self-esteem of the children, particularly those with additional learning needs. Some teachers suggested further activities for the subsequent term to reinforce the messages and refocus the children and their parents on their goals. Many 
Figure 3 Phase 3: Exploratory trial (2008-2010).
Process Evaluation

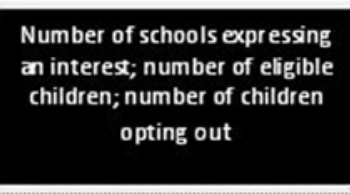

Number of children completing baseline measures

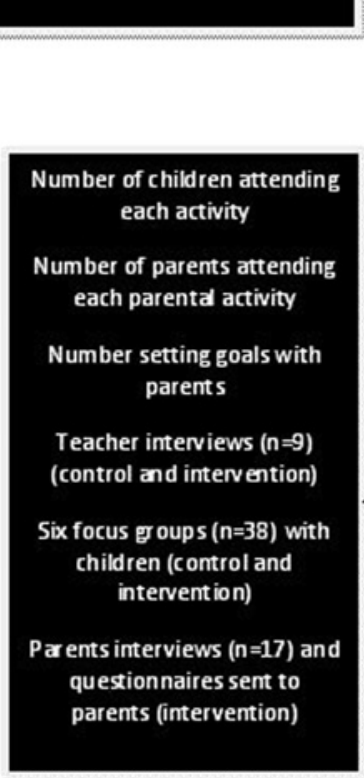

Number of children completing 18 month pos baseline measures

Number of children completing 24 month post baeline measures

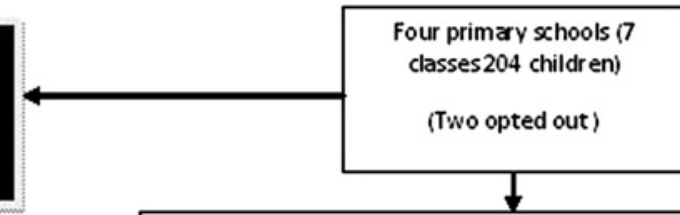
made by independent assessor) TV viewing/ screen based activity and food intake questionnaires $\mathrm{N}=202$

Accelerometry $\mathrm{N}=109 / 111$ (1 class per school)
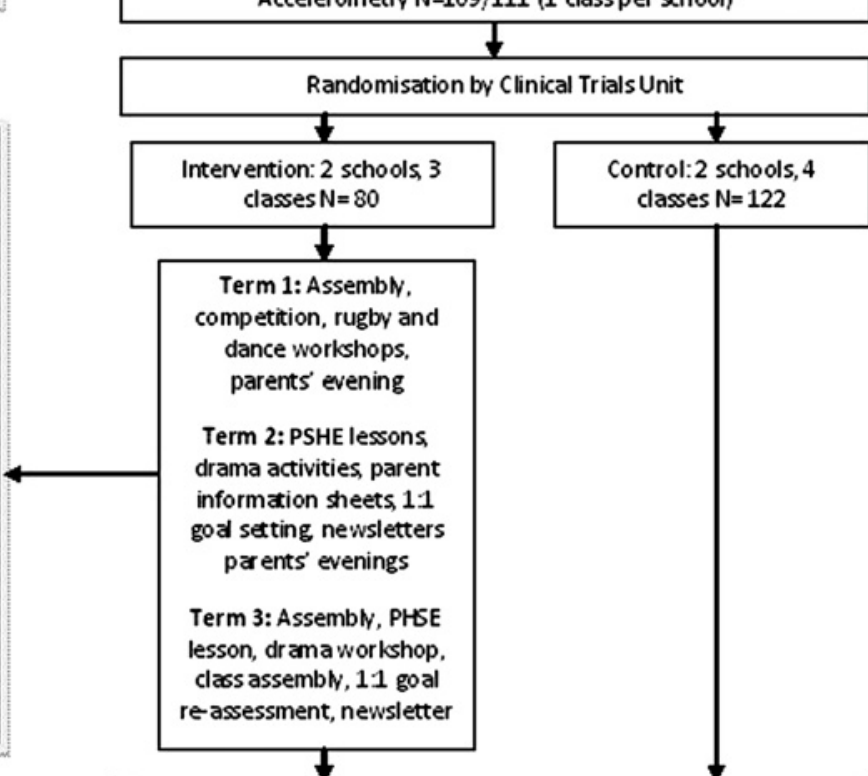

5 children moved to another area 1 opted out; 3 children withdrew
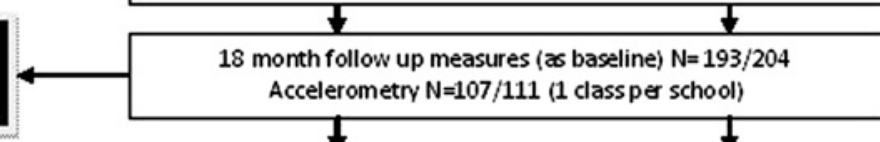

Children tracked to secondary school 11 opt out; 5 moved out of a eai

24 month follow up measures (height, weight, WC, \% BF $\mathrm{N}=187 / 204$ parents reported that their family had made lifestyle changes and that their child was willing to try new foods. The children enjoyed the drama activities and felt that they could relate to the characters within the drama framework who made them more motivated to set their own goals. Some children reported that they had started going to more after-school clubs.

\section{Implications}

An additional component was added to the intervention ('reinforcement activities') to take place at the beginning of Year 6, to motivate children to stick to their goals. In addition, minor refinements were made to the education lessons and the drama scripts to enhance delivery and continuity. Table 1 shows the final intervention components, how they relate to the HAPA model with their associated methods and agents of delivery. 
Table 1 Intervention components, processes of behaviour change and methods of delivery

\begin{tabular}{|c|c|c|c|}
\hline Component & $\begin{array}{l}\text { Process of behaviour } \\
\text { change }\end{array}$ & Method of delivery & Delivered by \\
\hline $\begin{array}{l}\text { Component 1: Engaging } \\
\text { schools, children and } \\
\text { families; spring term } \\
\text { (Year 5) }\end{array}$ & $\begin{array}{l}\text { Establish motivation and } \\
\text { create a receptive } \\
\text { environment }\end{array}$ & $\begin{array}{l}\text { Whole school assembly } \\
\text { Activity workshops (parents } \\
\text { observe) } \\
\text { Parents' evening (involving } \\
\text { performances by the children) } \\
\text { Newsletter articles }\end{array}$ & $\begin{array}{l}\text { Researcher } \\
\text { Professional sportsmen/ } \\
\text { dancers } \\
\text { Teachers/researcher/ } \\
\text { drama group } \\
\text { Researcher }\end{array}$ \\
\hline $\begin{array}{l}\text { Component 2: Intensive } \\
\text { Healthy Lifestyles Week, } \\
1 \text { week; summer term } \\
\text { (Year } 5 \text { ) }\end{array}$ & $\begin{array}{l}\text { Establish motivation by } \\
\text { developing children's } \\
\text { confidence and skills } \\
\text { and helping them make } \\
\text { decisions }\end{array}$ & $\begin{array}{l}\text { PSHE lessons (morning) } \\
\text { Drama (afternoon) (forum } \\
\text { theatre, role play, food tasting, } \\
\text { discussions, games, etc) }{ }^{\star}\end{array}$ & $\begin{array}{l}\text { Class teacher } \\
\text { Drama group }\end{array}$ \\
\hline \multirow[t]{4}{*}{$\begin{array}{l}\text { Component 3: Goal } \\
\text { setting-goals set during } \\
\text { week following drama; } \\
\text { summer term (Year } 5 \text { ) }\end{array}$} & \multirow[t]{4}{*}{$\begin{array}{l}\text { Take action by helping } \\
\text { children create an action } \\
\text { plan and implement goals }\end{array}$} & $\begin{array}{l}\text { Questionnaire to enable } \\
\text { children to reflect on snacking, } \\
\text { consumption of fizzy drinks and } \\
\text { physical activity }\end{array}$ & Researcher/class teacher \\
\hline & & $\begin{array}{l}\text { Goal setting sheet to go home } \\
\text { to parents to complete with child }\end{array}$ & Researcher/parents \\
\hline & & $\begin{array}{l}1: 1 \text { goal setting interview (goals } \\
\text { sent home to parents) }\end{array}$ & Researcher \\
\hline & & $\begin{array}{l}\text { Parents' evening (child } \\
\text { involvement-forum theatre) }\end{array}$ & Researcher/drama group \\
\hline \multirow[t]{6}{*}{$\begin{array}{l}\text { Component 4: } \\
\text { Reinforcement activities; } \\
\text { autumn term (Year 6) }\end{array}$} & \multirow[t]{6}{*}{$\begin{array}{l}\text { Keep children motivated by } \\
\text { helping them to monitor, } \\
\text { assess and adapt goals }\end{array}$} & $\begin{array}{l}\text { Whole school assembly } \\
\text { followed by drama workshops } \\
\text { to remind school/children of } \\
\text { messages and to prepare } \\
\text { class assembly }\end{array}$ & Drama group \\
\hline & & $\begin{array}{l}\text { PSHE lesson to remind children } \\
\text { of messages and goals }\end{array}$ & Class teacher \\
\hline & & $\begin{array}{l}\text { Children monitor goals on } \\
\text { personalised chart }\end{array}$ & $\begin{array}{l}\text { Class teacher } \\
\text { provides prompts }\end{array}$ \\
\hline & & $\begin{array}{l}\text { Class to deliver assembly about } \\
\text { the project to rest of school } \\
\text { (parents invited to attend) }\end{array}$ & $\begin{array}{l}\text { Children to all other } \\
\text { year groups in the school }\end{array}$ \\
\hline & & $\begin{array}{l}1: 1 \text { goal supporting interview } \\
\text { to discuss facilitators/barriers } \\
\text { and to plan new coping } \\
\text { strategies (renewed goals } \\
\text { sent home to parents) }\end{array}$ & Researcher \\
\hline & & Newsletter articles & Researcher \\
\hline
\end{tabular}

*The drama framework includes four characters, each represented by one of the actors, whose attributes related to the three healthy lifestyle messages (overall behavioural objectives). Children choose which of the characters they most resemble then work with that actor to help the character learn to change their behaviour.

PSHE, Personal, Social, and Health Education.

girls in the same intervention school withdrew prior to the 18-month measurements being collected; this coincided with the children being given a simple snacking and activity diary to complete over a 2-week period and feedback (teacher and parents) suggested this focused the girls too much on what they were eating and their parents felt they were restricting certain food groups.

Measurements were collected 18 month after baseline from 193/204 children, with 107/111 providing accelerometry data of which $85 \%(95 / 111)$ was useable. At collection of the 24-month anthropometric data, one girl (control school) did not want to be measured and five children (three control, two intervention) had moved out of the area, therefore data were obtained from $187 / 204$ children (92\% of the original cohort).

\section{Summary of anthropometric baseline data from the exploratory trial}

In the intervention schools, 24\% (18/80) of children were classified as overweight or obese compared to $26 \%$ $(31 / 122)$ in the control schools. One child (intervention school) was classified as being underweight. ${ }^{24}$ Mean body mass index (BMI) was 17.6 (SD 2.7) (95\% CI 17.27 to 18.02). Almost $20 \%(39 / 202)$ had a $\%$ body fat greater than or equal to the 85 th centile $^{25}$ and $43 \%$ (86/ 202) had a waist circumference greater than or equal to 
Table 2 Baseline characteristics of children

\begin{tabular}{|c|c|c|c|}
\hline & Intervention $(n=80)$ & Control $(n=122)$ & Total $(n=202)$ \\
\hline \multicolumn{4}{|l|}{ Demographics } \\
\hline Age (years), mean (SD) & $9.69(0.3)$ & $9.69(0.3)$ & $9.69(0.3)$ \\
\hline \multicolumn{4}{|l|}{ Sex } \\
\hline Male, \% (n) & $50(40)$ & $50(61)$ & $50(101)$ \\
\hline Female, \% (n) & $50(40)$ & $50(61)$ & $50(101)$ \\
\hline \multicolumn{4}{|l|}{ Anthropometric measurements } \\
\hline $\begin{array}{l}\text { Overweight or obese } \\
\text { ( } \geq 85 \text { th centile), }{ }^{25} \% \text { (n) }\end{array}$ & $23.7(18)$ & $26.1(31)$ & $25.1(49)$ \\
\hline BMI, mean (SD) (range) & 17.44 (2.6) (13.3-25.4) & 17.89 (2.8) (13.7-25.1) & $17.65(2.7)(13.3-25.4)$ \\
\hline $\begin{array}{l}\text { BMI SDs, mean (SD) } \\
\text { (range) }\end{array}$ & $0.3(1.1)(-2.3-2.5)$ & $0.4(1.1)(-2.0-2.9)$ & $0.3(1.1)(-2.3-2.9)$ \\
\hline
\end{tabular}

the 85 th centile. $^{26}$ Table 2 summarises child demographics and BMI status for the two groups.

\section{Process evaluation of the exploratory trial}

All children $(n=80)$ in the intervention schools participated in the healthy lifestyle week and $90 \%$ set goals with their families around lifestyle change. Seventy-five per cent of parents participated in one or more programme activity.

\section{User views}

Parents were adamant their children's diet and activity choices were their responsibility but felt school was a good place to reinforce these messages. Parents reported a greater acceptance of rules relating to screen-time and healthy eating in their child as well as initiation of discussion with other family members around healthy lifestyles.

Teachers agreed Year 5 was the right target group as children are gaining independence while still amenable to the messages. Some commented that the intervention had boosted the children's self-esteem, had a positive effect on the class socially and created additional opportunities to link with parents. Teachers felt using young actors to deliver the messages was key to achieving engagement with this age group.

Children were unanimous in their enjoyment of the drama activities and equally unequivocal that these activities should be carried out by people external to the school. They did not comment on the weighing and measuring and when this was brought up in the focus groups, dismissed it as 'fine'. The key message the children remembered was the importance of replacing unhealthy snacks with more healthy alternatives and replacing screen-based activities with more active pursuits which they enjoy.

\section{Implications}

Following the withdrawal of three girls from an intervention class, the snacking and activity diary activity has been withdrawn from component 4 (reinforcement activities). The education lessons were refined to include more self-monitoring activities for the children within the school and home environment in order keep the children focused on their goals in Year 6.
Summary of 18- and 24-month post-baseline anthropometric data from the exploratory trial

At 18 months, the proportion of overweight and obese children increased in the control schools from 26\% (31/ $122)$ to $32 \%(38 / 119)$ but remained at $24 \%(18 / 74)$ in the intervention schools. At 24 months, the proportion of overweight/obese children remained at 32\% (36/ 114 ) in the control schools and decreased slightly to $22 \%(16 / 73)$ in the intervention schools. Other anthropometric data and the results from the questionnaires and accelerometry will be reported elsewhere.

\section{DISCUSSION}

To date the evidence base for effective interventions to prevent and reduce childhood obesity is limited but suggests that a multi-component approach, addressing both sides of the energy balance and engaging families as well as the children, is more likely to be effective. ${ }^{16}$ Using an Intervention Mapping protocol ${ }^{18}$ involving literature reviews, extensive stakeholder consultation, expert workshops and three stages of piloting, we have created a programme of activities to engage and change behaviours at a school, child and family level. Such an intervention could also form part of a wider community approach to tackling obesity such as the programmes described in 'Romp and Chomp' and 'Being Active, Eating Well'. 1415 Unlike previous school-based interventions, ${ }^{27} 28$ HeLP activities have been ordered to promote and support behaviour change in children and their families using the HAPA model. ${ }^{23}$ Component 1 seeks to establish motivation and create a receptive context for the 'Healthy Lifestyles Week' (component 2). This component seeks to further motivate the children by building their confidence and skills and helping them make decisions. We worked closely with a local theatre company to design a drama framework built around four characters, each played by one of the actors whose attributes relate to our healthy lifestyle messages. Children have to choose which character they most resemble and then work with that character to help them change their behaviour. The actors became role models as they worked with the children in a range of interactive activities such as food tasting, making adverts, 
looking at ingredients and role play. The rationale for using the drama and the young actors as role models was to enthuse the children so much that they took the messages home to their parents and families and, crucially, encouraged them to come into the school and engage with the programme. Previous research has suggested that low income parents may be more likely to attend an event in which their children are participants than an educational event, (eg, eating and joint parentchild classes). ${ }^{29}$ Qualitative data revealed that the dynamic nature of the drama and the use of the young actors did indeed engage the children to such an extent that they talked exuberantly about the programme with their parents and siblings and encouraged them to attend events, particularly if they were going to be performing with the actors. Interestingly, it was the Year 5s (9-10-year-olds) who were best able to engage their families and translate the messages into possible behaviour change, which is why we decided to focus on this age group in subsequent pilots. The role play activities allowed us to teach the children how to communicate the healthy lifestyle messages to their family and seek their support in a subtle and positive manner. Component 3 moves the children on to helping them create an action plan and implement their goals with the support of their parents and component 4 helps them to remain motivated by delivering a range of reinforcement activities to monitor, assess and adapt their goals. Full details of each intervention component and their associated behaviour change techniques and methods of delivery are reported elsewhere.

One of the aims of the intervention was to explicitly affect the whole school environment by engaging all staff using staff meetings, whole school assemblies, competitions and parents' evenings. During the Healthy Lifestyles Week, the Year 5 teachers delivered the preprepared education lessons in the morning and then observed the theatre company deliver the interactive drama activities in the afternoon. Feedback from interviews and informal discussions with the teachers suggested that the observation of the drama led to an increase in their understanding and motivation which, in turn, led to greater support for, and involvement in, the programme. After pilot 2, teachers and the head teacher developed further activities relating to the healthy lifestyle messages after we had trialled the original ideas, which led to the addition of component 4 . The HeLP intervention has been specifically designed so that it can be adapted for use in different types of schools, increasing its generalisability, while still remaining standardised enough to maintain fidelity. The activities within the programme dovetail with the National Curriculum objectives for this age group. The drama framework is based around four characters with whom the children identify and these can be adapted for schools in a variety of different settings. In addition, the children drive the drama scenes as this is key to engagement and encouraging ownership of the healthy lifestyle messages. HeLP has been piloted in a range of schools with children from different socioeconomic groups and we have found no difference in the levels of engagement and parental involvement. One limitation, however, is that there is little ethic mix in schools in Exeter, but we would argue that the drama framework can be adapted to accommodate this.

As well as seeking to develop a novel and adaptable intervention that engages schools, children and their families, we sought to determine whether our proposed trial design and outcome measurements are feasible and acceptable for schools as well as individual children and their families. The baseline anthropometric data from phase 3 are very similar to national figures reported in the Health Survey for England (2008) and the National Child Measurement Programme (NCMP) (2009/2010). At 24 months, however, the percentage of overweight and obese children in the control schools increased by $6 \%$, mirroring the local NCMP data for 10-11-year-olds in Exeter, while decreasing by $2 \%$ in the intervention schools. Although the exploratory trial was not powered to detect statistically significant differences between intervention and control schools, the finding that the proportions overweight and obese remained at baseline levels in the intervention schools is encouraging, particularly in light of recent tracking data showing that the greatest increases in weight in a non-obese sample are between the ages of 7 and 11 years. ${ }^{30}$

Using the MRC framework for the development and evaluation of complex interventions, ${ }^{17}$ we have developed and refined a novel school-based programme to prevent and reduce obesity in children. We have demonstrated the feasibility and acceptability of the intervention and shown that it engages children, schools and families. We

\section{What is already known on this topic}

- There is little good quality evidence that existing interventions are effective in preventing and reducing childhood obesity.

- Interventions which aim to affect both diet and activity seem to show more promise than those targeting either alone.

\section{What this study adds}

- The Healthy Lifestyle Programme uses behavioural theory and novel interactive delivery methods to create the conditions to enable and support sustainable changes in behaviour for children and their families.

- The Healthy Lifestyle Programme is feasible to deliver within the context of the National Curriculum at Key Stage 2 and acceptable to children, their families and schools; preliminary results suggest that it may affect behaviours associated with overweight and obesity.

- The high levels of recruitment, retention and collection of outcome measurements in the exploratory trial suggest that a definitive trial is deliverable. 
have also demonstrated that we can recruit schools and children and collect baseline measurements prior to randomisation. Retention of children has been excellent with very few losses to follow-up at secondary school. Results from these pilot stages have provided us with sufficient information to suggest that the HeLP intervention should now be evaluated in a full-scale trial.

Acknowledgements The authors are very grateful to the participating schools, children and their families who gave up their time for the study. We would also like to acknowledge Sandy Akerman (Headbangers Theatre Company) who supported the design of the drama component of the intervention.

Funding Phases 1, 2 and 3 of development were funded by the Children's Research Fund (registered charity no. 226128) and the NIHR Research for Patient Benefit (RfPB) Programme. SL, KW and JL were partially supported by PenCLAHRC, the National Institute for Health Research (NIHR) CLAHRC for the Southwest Peninsula. This paper presents independent research commissioned by the National Institute for Health Research (NIHR). The views expressed are those of the author(s) and not necessarily those of the NHS, the NIHR or the Department of Health.

Competing interests None.

Ethics approval Ethics approval for each phase of the development and evaluation of the HeLP intervention was granted from the Peninsula College of Medicine and Dentistry Ethics Committee. This followed an approach to the NHS ethics committee who felt the study did not fall within their remit.

Contributors JL, KW and SC drafted the manuscript with SL providing critical revision. $\mathrm{JL}$ developed and supported the design and production of the intervention materials, coordinated the implementation of the intervention during pilot phases and conducted interviews with teachers and parents. JL and KW conducted the focus groups and SC performed the analyses on the anthropometric data. JL, KW and SL designed the study and obtained funding. KW will act as guarantor of the paper.

Provenance and peer review Not commissioned; externally peer reviewed.

Data sharing statement No additional data is available.

\section{REFERENCES}

1. Health Survey for England. 2008 Trend Tables. The NHS Information centre, 2009, http://www.ic.nhs.uk/pubs/hse08trends.

2. National Child Measurement Programme: Results from the School Year 2009/10: http://www.ic.nhs.uk/statistics-and-data-collections/ health-and-lifestyles/obesity/national-child-measurementprogramme-england-2009-10-school-year.

3. Gunnell DJ, Frankel SJ, Nanchahal K, et al. Childhood obesity and adult cardiovascular mortality: a 57-y follow-up study based on the Boyd Orr cohort. Am J Clin Nutr 1998;67:1111-18.

4. Serdula MK, Ivery D, Coates RJ, et al. Do obese children become obese adults? A review of the literature. Prev Med 1993;22:167-77.

5. Choi BC, Hunter DJ, Tsou W, et al. Diseases of comfort: primary cause of death in the 22nd century. J Epidemiol Community Health 2005;59:1030-4.

6. Lake JK, Power C, Cole TJ. Child to adult body mass index in the 1958 British birth cohort: associations with parental obesity. Arch Dis Child 1997;77:376-81.

7. Li L, Law C, Lo Conte R, et al. Intergenerational influences on childhood body mass index: the effect of parental body mass index trajectories. Am J Clin Nutr 2009;89:551-7.
8. Nielsen SJ, Popkin BM. Patterns and trends in food portion sizes, 1977-1998. JAMA 2003;289:450-3.

9. Jiménez-Pavón D, Kelly J, Reilly JJ. Associations between objectively measured habitual physical activity and adiposity in children and adolescents: systematic review. Int J Pediatr Obes 2010;5:3-18

10. Metcalf BS, Hosking J, Jeffery AN, et al. Fatness leads to inactivity, but inactivity does not lead to fatness: a longitudinal study in children (EarlyBird 45). Arch Dis Child. Published Online First: 23 June 2010. doi:10.1136/adc/2009.175927.

11. Marshall SJ, Biddle SJ, Gorely T, et al. Relationships between media use, body fatness and physical activity in children and youth: a meta analysis. Int J Obes Relat Metab Disord 2004;28:1238-46.

12. Wiecha JL, Peterson KE, Ludwig DS, et al. When children eat what they watch: impact of television viewing on dietary intake in youth. Arch Pediatr Adolesc Med 2006:160:436-42.

13. Halford JC, Gillespie J, Brown V, et al. Effect of television advertisements for foods on food consumption in children. Appetite 2004; $42: 221-5$

14. de Silva-Sanigorski AM, Bolton K, Haby M, et al. Scaling up community-based obesity prevention in Australia: background and evaluation design of the Health Promoting Communities: Being Active Eating Well initiative. BMC Public Health 2010;10:65.

15. de Silva-Sanigorski AM, Bell AC, Kremer $P$, et al. Reducing obesity in early childhood: results from Romp \& Chomp, an Australian communitywide intervention program. Am J Clin Nutr 2010;91:831-40.

16. Brown T, Summerbell C. Systematic review of school-based interventions that focus on dietary intake and physical activity levels to prevent childhood obesity: an update to the obesity guidance produced by the National Institute for Health and Clinical Excellence. Obes Rev 2008;10:110-41.

17. Medical Research Council. A New Framework for the Development and Evaluation of RCTs for Complex Interventions to Improve Health London: MRC, 2008. http://www.mrc.ac.uk/ complexinterventionsguidance.

18. Bartholomew K, Parcel GS, Kok G, et al. Planning Health Promotion Programmes: An Intervention Mapping Approach. San Francisco: Jossey-Bass, 2006.

19. NICE. Obesity: The Prevention, Identification Assessment and Management of Overweight and Obesity in Adults and Children. London: NICE, 2006.

20. Ryan RM, Patrick H, Deci EL, et al. Facilitating health behaviour change and its maintenance: Interventions based on self-determination theory. The European Health Psychologist 2008;10:2-5

21. Johnson B, Hackett AF. Eating habits of 11-14 year old school children living in less affluent areas of Liverpool, UK. J Hum Nutr Diet 1997;10:135-44.

22. Owens J, Maxim R, McGuinn M, et al. Television-viewing habits and sleep disturbance in school children. Pediatrics 1999;104:e27.

23. Schwarzer R. Self-efficacy in the adoption and maintenance of health behaviors: theoretical approaches and a new model. In: Schwarzer $\mathrm{R}$ ed. Self-efficacy: Thought Control of Action. London: Hemisphere, 1992:217-43.

24. Cole TJ, Freeman JV, Preece MA. Body mass index reference curves for the UK, 1990. Arch Dis Child 1995;73:25-9.

25. McCarthy HD, Cole TJ, Fry T, et al. Body fat reference curves for children. Int J Obes (Lond) 2006;30:598-602.

26. McCarthy HD, Jarrett KV, Crawley HF. The development of waist circumference percentiles in British children aged 5.0-16.9y. Eur $J$ Clin Nutr 2001;55:902-7.

27. James J, Thomas P, Cavan D, et al. Preventing childhood obesity by reducing consumption of carbonated drinks: cluster randomised controlled trial. BMJ 2004;22:1237-9.

28. Taylor RW, Mcauley KA, Williams SM, et al. Reducing weight gain in children through enhancing physical activity and nutrition: the APPLE project. Int J Pediatr Obes 2006;1:146-52.

29. Neumark-Sztainer D, Haines J, Robinson-O'Brien R, et al. 'Ready. Set. ACTION!' A theater-based obesity prevention program for children: a feasibility study. Health Educ Res 2008;24:407-20.

30. Hughes AR, Sherriff A, Lawlor DA, et al. Timing of excess weight gain in the Avon Longitudinal Study of Parents and Children (ALSPAC). Pediatrics 2011;127:e730-6. 